NBER WORKING PAPER SERIES

\title{
THE EFFECTS OF MEDICARE ADVANTAGE ON OPIOID USE
}

\author{
Laurence C. Baker \\ Kate Bundorf \\ Daniel Kessler
}

Working Paper 25327

http://www.nber.org/papers/w25327

\author{
NATIONAL BUREAU OF ECONOMIC RESEARCH \\ 1050 Massachusetts Avenue \\ Cambridge, MA 02138 \\ December 2018
}

We would like to thank Joel Ferguson and Grant Vaska for exceptional research support, and seminar participants at Stanford and Dartmouth for helpful comments. The views expressed herein are those of the authors and do not necessarily reflect the views of the National Bureau of Economic Research.

At least one co-author has disclosed a financial relationship of potential relevance for this research. Further information is available online at http://www.nber.org/papers/w25327.ack

NBER working papers are circulated for discussion and comment purposes. They have not been peer-reviewed or been subject to the review by the NBER Board of Directors that accompanies official NBER publications.

(C) 2018 by Laurence C. Baker, Kate Bundorf, and Daniel Kessler. All rights reserved. Short sections of text, not to exceed two paragraphs, may be quoted without explicit permission provided that full credit, including $\odot$ notice, is given to the source. 
The Effects of Medicare Advantage on Opioid Use

Laurence C. Baker, Kate Bundorf, and Daniel Kessler

NBER Working Paper No. 25327

December 2018

JEL No. I11,I13

\section{ABSTRACT}

Despite a vast literature on the determinants of prescription opioid use, the role of health insurance plans has received little attention. We study how the form of Medicare beneficiaries' drug coverage affects the volume of opioids they consume. We find that enrollment in Medicare Advantage, which integrates drug coverage with other medical benefits, significantly reduces beneficiaries' likelihood of filling an opioid prescription, as compared to enrollment in a standalone drug plan. Approximately half of this effect was due to fewer fills from prescribers who write a very large number of opioid prescriptions.

Laurence C. Baker

Department of Health Research \& Policy

HRP Redwood Bldg, Rm T110

Stanford University

Stanford, CA 94305-5405

and NBER

laurence.baker@stanford.edu

Kate Bundorf

Health Research and Policy

Stanford University

HRP T108

Stanford, CA 94305-5405

and NBER

bundorf@stanford.edu
Daniel Kessler

Stanford University

434 Galvez Mall

Stanford, CA 94305

and NBER

fkessler@stanford.edu

An online appendix is available at http://www.nber.org/data-appendix/w25327 
$\underline{\text { Introduction }}$

Since 2000, the U.S. has experienced a dramatic increase in overdose deaths, opioid use disorder, and other harms from inappropriate use of prescription opioids (Paulozzi, Jones, Mak, et al. 2011). This rise in harms has occurred contemporaneous with a tripling in the amount of opioids that were prescribed from 1999-2015 (Guy, Zhang, Bohm, et al. 2017). By 2015, the amount of opioids prescribed per person in the U.S., 640 morphine milligram equivalents (MMEs), was enough for every American to be medicated around the clock for three weeks, equivalent to $5 \mathrm{mg}$ hydrocodone every 4 hours. $^{1}$

Several indicators suggest at least some of this expansion in opioid use is medically inappropriate. Physicians in counties in the highest quartile of prescribing write six times the amounts (in MMEs) than those in the lowest quartile, and most of this variation cannot be explained by conventional patient, area socioeconomic, or market characteristics (Guy, Zhang, Bohm, et al. 2017). Medical-claims-based indicators suggest that inappropriate prescribing behavior is common. In a sample of approximately 3 million commercially-insured adults who received an opioid prescription, about a quarter had at least one indicator of inappropriate prescribing, and 5.8 percent had two or more (Liu, Logan, Paulozzi, et al. 2013). Other work shows that physicians trained at less-selective medical schools write significantly more opioid prescriptions than those trained at more-selective schools (Schnell and Currie 2017).

These circumstances offer health plans the opportunity to improve prescribing practices through management of their physicians. For two reasons, Medicare Part D is an ideal setting in which to investigate the extent to which plans have taken advantage of this opportunity.

First, inappropriate use of opioids in Medicare Part D is an important policy problem. Medicare Part D is a voluntary (but highly subsidized) outpatient prescription drug benefit that

\footnotetext{
${ }^{1}$ http://www.cdc.gov/vitalsigns/opioids/infographic.html, accessed September 10, 2018.
} 
started in 2006. All 59 million Medicare beneficiaries are entitled to prescription drug coverage through a private plan approved by the Centers for Medicare and Medicaid Services (CMS); in 2017, more than 42 million beneficiaries enrolled in a Part D plan (Kaiser Family Foundation 2017).

Since the adoption of Part D, Medicare has become the largest purchaser of prescription opioids, covering about 20-30\% of total U.S. spending on opioids (Zhou, Florence, and Dowell 2016). Several indicators suggest that there is inappropriate opioid use in Medicare. Many Medicare beneficiaries have concurrent opioid prescriptions from multiple prescribers (Jena, Goldman, Weaver, et al. 2014). Opioid prescribing in Medicare is concentrated among a small number of high prescribers: in the Part D program, 35\% of opioids by value were prescribed by the top $1 \%$ of prescribers, and $78 \%$ were prescribed by the top $10 \%$ of prescribers (Chen, Humphreys, Shah et al. 2016). According to the Office of the Inspector General of the Department of Health and Human Services, "extreme use” and "questionable prescribing” have put almost 90,000 beneficiaries at serious risk for opioid misuse or overdose; almost half of beneficiaries from some states (Alabama, Mississippi, and Louisiana) received at least one opioid prescription in 2016 (HHS OIG 2017). In addition, the consequences of opioid prescribing in Medicare may spill over to the population more broadly: the expanded access to opioids resulting from the adoption of Part D increased opioid misuse among the Medicareineligible population (Powell, Pacula, and Taylor 2015).

Second, the way that Part D covers prescription drugs has created a natural experiment with which to evaluate the effects of insurer strategies on inappropriate opioid use. Part D takes two different forms in which insurers have very different incentives and abilities to control inappropriate use of prescription opioids. Beneficiaries can obtain Part D coverage through their 
choice of either a stand-alone prescription drug plan (PDP) that supplements traditional fee-forservice Medicare, or a Medicare Advantage prescription drug plan (MA-PD) that is integrated with a Medicare Advantage plan that covers all Medicare benefits including drugs. While the administrator of a PDP has essentially no incentive or ability to manage the physicians who prescribe covered drugs, the administrator of a MA-PD plan has the incentive to account for the spillover effects of prescription drug use on the cost of care overall and can choose which physicians to include in its network and how it manages care. Previous work has found that the integration of MA-PD prescription drug coverage with the other benefits provided by Medicare Advantage plans has some beneficial effects: MA-PD plans have more generous prescription drug coverage than PDP plans, which translates into higher prescription drug utilization by enrollees, driven by drugs that reduce overall medical expenditures and treat chronic conditions (Starc and Town 2018).

These same forces could also lead to less opioid use in MA-PD versus PDP plans. Yet, no work has investigated whether this is the case. This paper seeks to fill this gap. We use Medicare Part D claims to compare the rate of opioid prescriptions for patients enrolled in in MA-PD plans versus PDPs. For each beneficiary, we construct four measures of the amount of opioids prescribed in 2014: any prescription for an opioid; any prescription for an opioid from a high prescriber, defined as the top $1 \%$ of prescribers in terms of number of opioid prescriptions written; any prescription for $>7$ days' supply of an opioid, conditional on any opioid; and any prescription for $>7$ days' supply of an opioid from a high prescriber, conditional on any opioid from a high prescriber.

We estimate the effects on the amount of opioids prescribed of enrollment in an MA-PD plan using instrumental variables. For our instrument we use a discontinuity in the rules 
governing payments to MA-PD (but not PDP) plans that give greater payments to MA-PD plans that cover beneficiaries who live in counties that are part of Metropolitan Statistical Areas (MSAs) with populations of 250,000 or more. These counties are sometimes described as "urban floor” counties. The sharp difference in payment rates at the urban floor creates incentives for MA-PD plans to reduce premiums and increase the generosity of benefits in counties above versus below the cutoff. The lower premiums and expanded benefits enhance beneficiaries' incentives to enroll in Medicare Advantage. The induced incremental enrollment, in turn, allows us to identify the effect of MA-PD plans on opioid prescription rates independent of any unmeasured characteristics of beneficiaries or areas - as long as the urban floor is not correlated with these unmeasured characteristics. This approach has been used in other work to identify the effect of enrollment in Medicare Advantage on other outcomes, such as the hospitalization rate, medical spending, prescription drug use overall, and mortality (e.g., Afendulis, Chernew, and Kessler 2017; Cabral, Geruso, and Mahoney 2018; Duggan, Starc, and Vabson 2016; Starc and Town 2018).

\section{Previous Literature}

There is a vast literature on the social and economic determinants of the rise in use of and harms from opioids (see, e.g., Dasgupta, Beletsky, and Ciccarone 2018 for a comprehensive review). Among other factors, health policy researchers have highlighted inappropriate prescribing. In response, states have adopted numerous policies like prescription drug monitoring programs (PDMP), statewide databases that gather information from pharmacies on the dispensing of controlled substances. Several studies have found that mandated use of PDMPs can help prescribers identify patients at high risk of misuse (Wen, Shcackman, Aden, 
and Bao 2017; Buchmueller and Carey 2017; Sacco, Duff, and Sarata 2018; Bao, Wen, Johnson, et al. 2018). Other work has found that augmenting mandated use of PDMPs with laws requiring special registration of pain clinics, which prescribe opioids and other controlled substances to patients in large quantities, can reduce opioid prescriptions and overdose death rates (Dowell, Zhang, Noonan, et al. 2016). Insurers have also recognized that the techniques they employ to reduce low-value care in other settings might also be used to reduce inappropriate prescription of opioids (Laverdier, Pereyda, and Silva 2016).

Two case studies have evaluated the effectiveness of insurers' attempts to encourage more judicious use of opioids. One study found that a utilization management program implemented by Blue Cross/Blue Shield of Massachusetts - which required prescribers to conduct a risk assessment for patient abuse, to obtain prior authorization for certain opioid prescriptions, and to limit quantities - reduced the rate of new opioid prescriptions and the share of enrollees with a current opioid prescription (Garcia, Dodek, Kowalski, et al. 2016). Another study found that a prior authorization requirement implemented by Blue Shield of California which required approval for extended-release (ER) oxycodone, one of the most-misused opioids - decreased the rate of ER oxycodone prescriptions but did not significantly decrease the overall use of opioids in terms of MME per enrollee (Barnett, Olenski, Thygeson, et al. 2018). Although these studies have provided valuable evidence about the effectiveness of two particular insurers' strategies, neither has provided systematic evidence about the broader effectiveness of insurers' efforts to address inappropriate prescribing of opioids - and no work has examined the effect of the Medicare Advantage program on opioid use in Medicare Part D.

There is some suggestive evidence that enrollees in MA-PD plans have lower rates of prescription opioid use than enrollees in PDPs. Approximately one-quarter of enrollees in 
United's MA-PD plans had an opioid prescription in 2015 (UnitedHealth Group 2017) as compared to one-third of enrollees in Part D overall (HHS OIG 2017). However, the difference in opioid use rates between these two studies does not account for numerous factors, such as enrollees' demographic characteristics, health status, intensity of prescription drug use overall, prior opioid use, and location.

\section{$\underline{\text { Data and Models }}$}

Data. We construct a cohort of a 20\% random sample of Medicare beneficiaries in 2014. We restrict our cohort to beneficiaries age 66 or older on January 1, 2014 who became and were currently eligible because of their age; who were not dual (Medicaid) enrollees; were alive and enrolled in a single PDP or MA-PD plan for all of 2014; were not enrolled in a private fee-forservice plan (because these plans have been phased out and so are not relevant to current policy); and were enrolled in some PDP or MA-PD plan in 2013 (to obtain historical information on each beneficiary). For each beneficiary, we obtain all outpatient prescription drug claims for 2014. We match to each claim by National Drug Code whether or not the claim was for an opioid, according to the CDC's classification system, ${ }^{2}$ and calculate the number of days' supply of opioids.

Returning to the set of prescription drug claims for 2014, we calculate for each prescriber the number of opioid prescriptions that s/he wrote, and then rank her according to this statistic. We flag claims for opioids written by the top $1 \%$ of opioid prescribers. Then, considering only flagged claims, we calculate for each beneficiary the number of days' supply of opioids in 2014 - that is, the days' supply written by a high prescriber.

\footnotetext{
${ }^{2}$ Available at https://www.cdc.gov/drugoverdose/data-files/cdc_mme table_sept2017.xlsx, accessed September 16, 2018.
} 
Table 1a reports means (and standard deviations) of our dependent variables for all nonrural Medicare beneficiaries and beneficiaries from MSAs with population of 100,000400,000. For beneficiaries from MSAs in this population range, it also presents means by county floor status (in MSAs with above versus below 250,000 population), along with 95 percent confidence intervals and p-values from difference-in-means hypothesis tests (based on heteroskedasticity-robust standard errors clustered at the county level).

The first row of Table 1a shows that floor status affects MA enrollment, as previous research has shown. Beneficiaries in urban floor counties were significantly more likely to enroll in a MA-PD plan: 43.9 percent of beneficiaries in counties just above the floor were enrolled in a MA-PD plan, versus 30.2 percent in counties just below $(p<0.001)$. The second row shows that beneficiaries in urban floor counties were significantly less likely to be prescribed an opioid. In 2014, 30.8 percent of beneficiaries in counties just above the floor had at least one opioid prescription in 2014, versus 31.9 percent in those just below $(p=0.062)$. According to the ratio of these two differences -- the Wald estimate of the effect of MA-PD enrollment on opioid prescription rates -MA-PD enrollment reduces opioid prescription rates. Per percentage point of likelihood of MA-PD enrollment, a Medicare beneficiary in 2014 was 0.08 percentage points less likely to be prescribed an opioid $(=(30.8-31.9) /(43.9-30.2))$. This translates into a reduction in opioid prescription rates due to MA-PD enrollment of 8 percentage points $(=100 \times 0.08)$, or approximately 25 percent $(\approx 8 / 31.3)$. Approximately half of this effect is due to reductions in prescriptions from high prescribers $(0.5$ percentage point $=$ $4.0-4.5$ percentage points), although the raw difference in prescriptions from high prescribers is not statistically significant at conventional levels $(p=0.134)$. 
Figures 1 and 2 present the Wald estimate graphically. Each point represents a county. The lines represent quadratic functions of MSA population fitted to the points by (populationweighted) least squares. The lines show that, at the 250,000 population discontinuity, the effect of the urban floor on MA enrollment is slightly smaller than the average effect over the 100,000 $-400,000$ band. As we show in our robustness checks below, this causes IV estimates of the effect of MA on opioid use to grow as the bandwidth shrinks.

The bottom panels of Table 1a present statistics for the subset of beneficiaries with an opioid prescription, either from any prescriber or from a high prescriber. The bottom panels show that, conditional on any opioid, the volume of opioid prescriptions does not differ across the urban floor ( $p=0.620$ and 0.954 , respectively).

Table $1 \mathrm{~b}$ presents descriptive statistics of our independent variables, including characteristics of beneficiaries, counties, and hospital markets. We obtain beneficiaries’ demographic characteristics (age on January 1, 2014; male or female gender; and Black or nonBlack race) from the Medicare enrollment files. We match to each beneficiary several characteristics of county of residence in 2014 that may affect MA-PD enrollment and opioid use, including the following: the number of opioid prescriptions per person (from CDC) ${ }^{3}$; the county average risk score of Medicare beneficiaries (from CMS) ${ }^{4}$; the median income, land area per 1000 residents, primary care physicians per 1000 residents, and percent of residents in poverty, disabled, and on Medicaid (from AHRF) ${ }^{5}$; and the percent of residents who were obese and

\footnotetext{
${ }^{3}$ Available at https://www.cdc.gov/drugoverdose/maps/rxcounty2014.html, accessed September 16, 2018.

${ }^{4}$ Calculating using https://www.cms.gov/Medicare/HealthPlans/MedicareAdvtgSpecRateStats/Downloads/ffs2014.zip, https://www.cms.gov/Medicare/MedicareAdvantage/Plan-Payment/Downloads/2014paymentdata.zip, and https://www.cms.gov/Research-Statistics-Dataand-Systems/Statistics-Trends-and-Reports/MCRAdvPartDEnrolData/Monthly-Enrollment-by-Contract-Plan-StateCounty-Items/Monthly-Enrollment-by-CPSC-2014-12-Fixed.html, accessed September 16, 2018.

${ }^{5}$ Available at https://data.hrsa.gov//DataDownload/AHRF/AHRF_2016-2017.ZIP, accessed August 30, 2018; the most recent available Medicaid enrollment rates were from 2012.
} 
diabetic (from CDC) ${ }^{6}$ We also match to each beneficiary several characteristics of the hospital market of her zip code of residence including the Hirschman-Herfindahl index of competitiveness; bed capacity; the density of for-profit and non-profit hospitals (comparison category is public hospitals); the density of $<100$ and $>300$ bed hospitals (comparison category is 100-300 bed hospitals); and the density of hospitals that are integrated with their physicians, teaching facilities, and members of a system. ${ }^{7}$

In most dimensions (i.e., the overall opioid prescription rate, the availability of primary care physicians, the percentage of county residents who were disabled, obese, diabetic, or on Medicaid), urban floor counties do not differ significantly in ways that would suggest that Medicare beneficiaries who lived in them would be more or less likely to have an opioid prescription. Although urban floor counties differ from others along some dimensions that would suggest their residents would be more likely to have an opioid prescription (e.g., a higher county average Medicare risk score, $p=0.048$ ), they also differ in ways that would suggest their residents would be less likely to have an opioid prescription (e.g., higher median income, $p=$ 0.005 , and lower poverty rates, $p=0.068$ ). Not surprisingly, urban floor counties (which are, by construction, in more populous MSAs) have less land area per person $(p<0.001)$, more competitive hospital markets $(p<0.001)$, and more large, teaching hospitals $(p=0.002$ and $p=$ 0.034 , respectively).

Table 2 shows that the distribution of opioid prescriptions across prescribers is highly skewed. To be in the top percentile of prescribers in 2014, a prescriber would have to have written 217 opioid prescriptions to a 20\% sample of Medicare beneficiaries; if half of such prescribers’ patients were Medicare beneficiaries (and their prescribing behavior was age-

\footnotetext{
${ }^{6}$ Available at http://www.countyhealthrankings.org/sites/default/files/2018CountyHealthRankingsData-v1.xls, accessed September 16, 2018.

${ }^{7}$ Details of the construction of these variables are in the Online appendix.
} 
invariant), that would imply that prescribers in the top percentile wrote at least 2,170 opioid prescriptions in $2014(=217 * 5 * 2)$, or at least 8.3 opioid prescriptions per business day (= 2,170 / 260). These $1 \%$ of high prescribers accounted for 26.9 percent of all opioid prescriptions written to Medicare beneficiaries. At the same time, the bottom half of prescribers in Medicare wrote $<1$ opioid prescription, or (under the same assumptions above) at most 10 opioid prescriptions in 2014.

Models. Our basic models are of the form

$$
Y_{i z c}=\alpha+M A_{i z c} \beta+X_{i z c} \gamma+M K T_{z c} \delta+W_{c} \eta+\varepsilon_{i z c},
$$

where

$i$ indexes beneficiaries, $z$ indexes zip codes, $c$ indexes counties;

$Y_{i z c}=1$ if $i$ experiences an outcome, such as the receipt of an opioid prescription;

$M A_{\text {izc }}=1$ if $i$ is enrolled in a MA-PD plan, $=0$ if enrolled in a PDP plan;

$X_{i z c} \quad$ is a vector of indicator variables capturing the age, gender, and race of $i$;

$M K T_{z c}$ is a vector of variables capturing the characteristics of $i$ 's local health care market of $i$;

$W_{c}$ is a vector of variables capturing the socioeconomic and other characteristic of $i$ 's county, including the county's MSA's population in 2000 (on which its floor status is based, and in selected models, its square) ${ }^{8}$; and

$\varepsilon_{i z c} \quad$ is an error term that we allow to be arbitrarily correlated within each county.

We begin by estimating (1) by OLS. However, because enrollment in MA-PD is optional, OLS estimates of $\beta$ are potentially subject to selection bias. To the extent that beneficiaries who choose an MA-PD plan are unobservably healthier, or subject to other unmeasured factors that influence their propensity to receive an opioid prescription, conventional

\footnotetext{
${ }^{8}$ Although some regression discontinuity analyses in health economics research control for higher-order polynominals of the forcing variable, we include only linear and quadratic terms as recommended by Gelman and Imbens (2018). If we include a cubic term (results not reported), our results grow in magnitude.
} 
estimates of the effect of MA-PD enrollment will represent a combination of the program's true causal impact and unmeasured differences in its patient population.

We also present IV estimates of $\beta$, with the urban floor as an instrument. Thus the first stage of our IV models are of the form

$$
M A_{i z c}=\alpha^{*}+F L R_{c} \beta^{*}+X_{i z c} \gamma^{*}+M K T_{z c} \delta^{*}+W_{c} \eta^{*}+\varepsilon^{*} i z c,
$$

where $F L R_{c}=1$ if county $c$ is in a MSA with population greater than 250,000, $=0$ otherwise. The validity of our instrumental variables estimates depends on the assumption that residency in an urban floor county is not correlated with unmeasured determinants of opioid prescribing for Medicare beneficiaries. To make this assumption as plausible as possible, we limited our analysis to beneficiaries who live in counties that are part of MSAs with populations between 100,000 and 400,000 (in order to make counties affected by our instrumental variable similar to those that are not affected); controlled for other characteristics of counties that might be correlated with MSA size and opioid use (as well as a linear and quadratic function of MSA size); and conducted several robustness checks that we describe in detail below.

\section{$\underline{\text { Results }}$}

Table 3 presents estimates of $\beta$ and $\beta^{*}$ (and selected elements of $\eta$ and $\eta^{*}$ for comparison purposes) from (1) and (2), where $Y_{i z c}=1$ if beneficiary $i$ filled at least one opioid prescription in 2014. Column (1) presents estimates of $\beta^{*}$ and $\eta^{*}$ from the first stage of our IV models.

Column (1) shows that the effect of the urban floor on MA enrollment from (2) - that is, holding constant all of our individual, health care market, and county characteristics (including a quadratic in MSA population) -- is slightly smaller than the raw effect (compare 11.9 percentage 
points, Table 3, to 13.7 percentage points, Table 1), with the effect of the urban floor highly significant $(p<0.001)$.

Columns (2) and (3) present OLS and IV estimates, respectively, of $\beta$ and $\eta$ from (1). According to OLS, enrollment in a MA-PD versus PDP plan leads to a 2.8 percentage point decline in the likelihood of an opioid prescription. The IV estimate of 11.6 percentage points is approximately four times larger than (but not statistically significantly different from) the OLS estimate. ${ }^{9}$ On a base likelihood of an opioid prescription of 31.3 percentage points, this amounts to an effect of $9(=2.8 / 31.3)$ to 37 percent $(=11.6$ / 31.3).

The effect of MA on opioid use is of the same order of magnitude as the effect of living in a socioeconomically-advantaged county. A one-standard-deviation decrease in the rates of disability, obesity, and poverty in a county is associated with an approximately 4 percentage point decrease in the opioid prescription rate $(0.04 \approx 0.430 * 0.043+0.350 * 0.031+0.227 * 0.044$, based on estimates of $\eta$ from column (3) and standard deviations from Table 1b); this amounts to between $35(\approx 4 / 11.6$, based on IV estimate) and 140 percent $(\approx 4 / 2.8$, based on OLS estimate) of the effect of MA-PD enrollment.

Columns (4) and (5) present OLS and IV estimates, respectively, of $\beta$ and $\eta$ from (2), where $Y_{\text {izc }}=1$ if beneficiary $i$ filled $>7$ days of opioid prescriptions in 2014, conditional on filling at least one opioid prescription. According to OLS, enrollment in a MA-PD versus PDP plan leads to a 1.4 percentage point decline in the likelihood of more than a week of opioids, conditional on any opioid; the IV effect is very small ( $<0.1$ percentage point) and statistically insignificant. These effects are much smaller (at most $0.02=1.4$ / 68.4) than the effect of enrollment in a MA-PD plan on any opioid, indicating the impact of MA-PD enrollment is largely on the extensive margin of opioid use.

\footnotetext{
${ }^{9}$ The 95 percent confidence interval around the IV estimate has a lower bound of $-2.52(=-11.592-(1.96 * 4.629))$.
} 
Table 4 replicates Table 3, but with $Y_{i z c}=1$ if beneficiary $i$ filled at least one opioid prescription in 2014 from a high prescriber. Column (1) of Table 4 replicates column (1) from Table 3; we report it for convenience, since the first stage of is invariant to the choice of $Y_{\text {izc }}$. According to the IV estimate in column (3), MA-PD enrollment reduces the likelihood of an opioid from a high prescriber by 6.4 percentage points; this effect is extremely large, with a 95 percent confidence interval that includes the average likelihood of an opioid from a high prescriber. The point estimate of $\beta$ is around half as large as the point estimate of $\beta$ from Table 3: the effect of MA-PD enrollment on the likelihood of an opioid from a high prescriber accounts for approximately half of the effect of enrollment in a MA-PD plan on the likelihood of any opioid. As was the case with the effect on the intensive margin of opioid use more generally, the effect of MA-PD enrollment on the intensive margin of the use of opioids from high prescribers is small and statistically insignificant.

Table 5 presents results from four robustness checks. Columns (1) and (2) report estimates from variants of (1) and (2) that exclude the quadratic term in the forcing variable; the estimates are virtually unchanged. Columns (3) and (4) include a control for the county-average opioid prescription rate. By construction, this variable is endogenous, as it contains the effect of the urban floor through the floor's effect on Medicare beneficiaries’ opioid prescriptions. Nonetheless we report estimates from models that control for it to investigate the extent to which omitted characteristics of counties that affect the demand for or supply of opioids more broadly are correlated with the urban floor. ${ }^{10}$ The results show this is not an important concern. Although the effect of MA-PD enrollment declines slightly, it remains statistically significant and economically important. Columns (5) and (6) report estimates from models based on

\footnotetext{
${ }^{10}$ Ideally, we would include a control for the county average opioid prescription rate to patients other than Medicare beneficiaries, but this information is not available.
} 
beneficiaries who live in the 92 counties with MSA population in a more narrow bandwidth (200,000 - 300,000). Consistent with Figures 1 and 2, the estimated effect of MA-PD enrollment on opioid use grows, although the 95 percent confidence intervals around the estimate from the restricted sample of counties includes the estimate from the 100,000 - 400,000 sample. Columns (7) and (8) restrict the sample to the $69 \%(=370,529$ / 536,481) of beneficiaries who were opioid-naïve, defined as those without an opioid prescription in 2013. Estimates from this restricted model show that MA-PD enrollment has a smaller effect on this larger population, which implies that the effect of MA-PD enrollment is larger for prior opioid users.

\section{Discussion}

Inappropriate use of opioids in Medicare Part D, and in the U.S. in general, is an important social problem. Yet, except for two important case studies of the effect of individual insurers' policy changes on opioid prescribing in populations of commercially-insured enrollees, there is no systematic evidence about the effectiveness of health plans' efforts to address inappropriate use of prescription opioids, and no evidence at all of the effectiveness of health plans' efforts to address inappropriate use in the Medicare program.

The fact that the Part D program covers prescription drugs in two very different ways either through a stand-alone PDP that works as a supplement to traditional fee-for-service Medicare, or through a MA-PD plan that is integrated with a (managed) Medicare Advantage plan - creates a natural experiment for evaluating insurers' efforts to reduce inappropriate opioid prescription practices. However, because enrollment in a MA-PD plan is optional, conventional regression estimates of the effect of MA-PD enrollment are potentially subject to selection bias. 
In this paper, we offer a new approach to evaluating the impact of enrollment in a MAPD plan on the likelihood of receiving an opioid prescription and the volume of opioids prescribed. We use an instrumental variables approach that has been validated in several papers to isolate the effect of MA-PD enrollment from the effects of unmeasured characteristics that may simultaneously influence prescription opioid use and MA-PD enrollment.

We report three key findings. First, based on our IV estimates, enrollment in a MA-PD plan reduced the likelihood of filling an opioid prescription by 11.6 percentage points in 2014 ( $p$ $=0.012$ ), amounting to a 37 percent reduction relative to the average likelihood of 31.3 percentage points. OLS estimates of the effect of MA-PD enrollment are around one-fourth as large (2.8 percentage points), but within the 95 percent confidence interval around the IV estimate. Second, slightly more than half of the 11.6-percentage-point reduction came from the effect of MA-PD enrollment on beneficiaries' likelihood of an opioid prescription from a high prescriber, defined as a prescription from the top $1 \%$ of opioid prescribers. Third, for those beneficiaries with an opioid prescription (or an opioid prescription from a high prescriber), MAPD enrollment does not have a statistically significant effect on the number of days' supply of opioids received, either from any prescriber or a high prescriber.

Our approach has several limitations. Because our instrument operates at the county level, our IV estimates represent a combination of the direct plus the spillover effects of MA-PD enrollment. ${ }^{11}$ Distinguishing the direct from the spillover effects would require an additional instrument that operates at the individual level, an instrument that we do not have. Because there are likely to be spillover effects from MA-PD to PDP plans (Baker 1997; Chernew, DeCicca, and Town 2008), our estimates likely overstate the causal impact of moving an individual

\footnotetext{
${ }^{11}$ The direct effect is the reduction in opioid use obtained by PDP enrollees who switch to MA-PD; the spillover effect is the reduction in opioid use obtained by PDP enrollees who stay in PDP, as a result of the switchers' influence on the treatment of the stayers.
} 
beneficiary from a PDP to a MA-PD plan. In addition, our estimates can only be interpreted as causal for an individual PDP enrollee under the assumption that the local average treatment effect estimated around the urban floor (with a likelihood of MA enrollment of around 37 percent) applies across the distribution of likelihoods of MA enrollment - an assumption that may be incorrect. For these reasons, our estimates should be interpreted as the market-wide effect of an incremental increase in the likelihood of MA enrollment near the current average. Because we did not examine the effect of MA-PD enrollment on measures of health outcomes, we cannot say definitively that enrollment in MA-PD reduced only inappropriate opioid use. However, two aspects of our results suggest that it did. First, the fact that previous work found that MA-PD enrollees had higher prescription drug utilization overall means that the reduction in opioid use in MA-PD was targeted rather than an artifact of a broader effort to restrict access to treatment. Second, we found that the reduction in opioid use by MA-PD enrollees was disproportionately due to a reduction in prescriptions from the top $1 \%$ of opioid prescribers. Although the top $1 \%$ of prescribers accounted for approximately one-seventh of the average beneficiary's likelihood of an opioid prescription $(\approx 4.2$ percentage points / 31.3 percentage points, Table 1a), slightly more than half of the reduction in the opioid prescription rate due to MA-PD enrollment overall came from the effect of MA-PD on beneficiaries' likelihood of an opioid prescription from a high prescriber. We did not determine whether this was due to exclusion of high prescribers from Medicare Advantage plans' networks, other aspects of benefit design that encourage patients to avoid high prescribers, or other changes in treatment that reduce the need for opioids; this is a topic for future research.

Our results support the conclusions of Starc and Town (2018) that integration of prescription drug coverage with the other benefits provided by Medicare Advantage plans 
improves the quality of care. The extent to which this occurs in commercial insurance coverage for the non-elderly is another topic for future research. 
Figure 1: County-Average Medicare Advantage Enrollment, By MSA Population

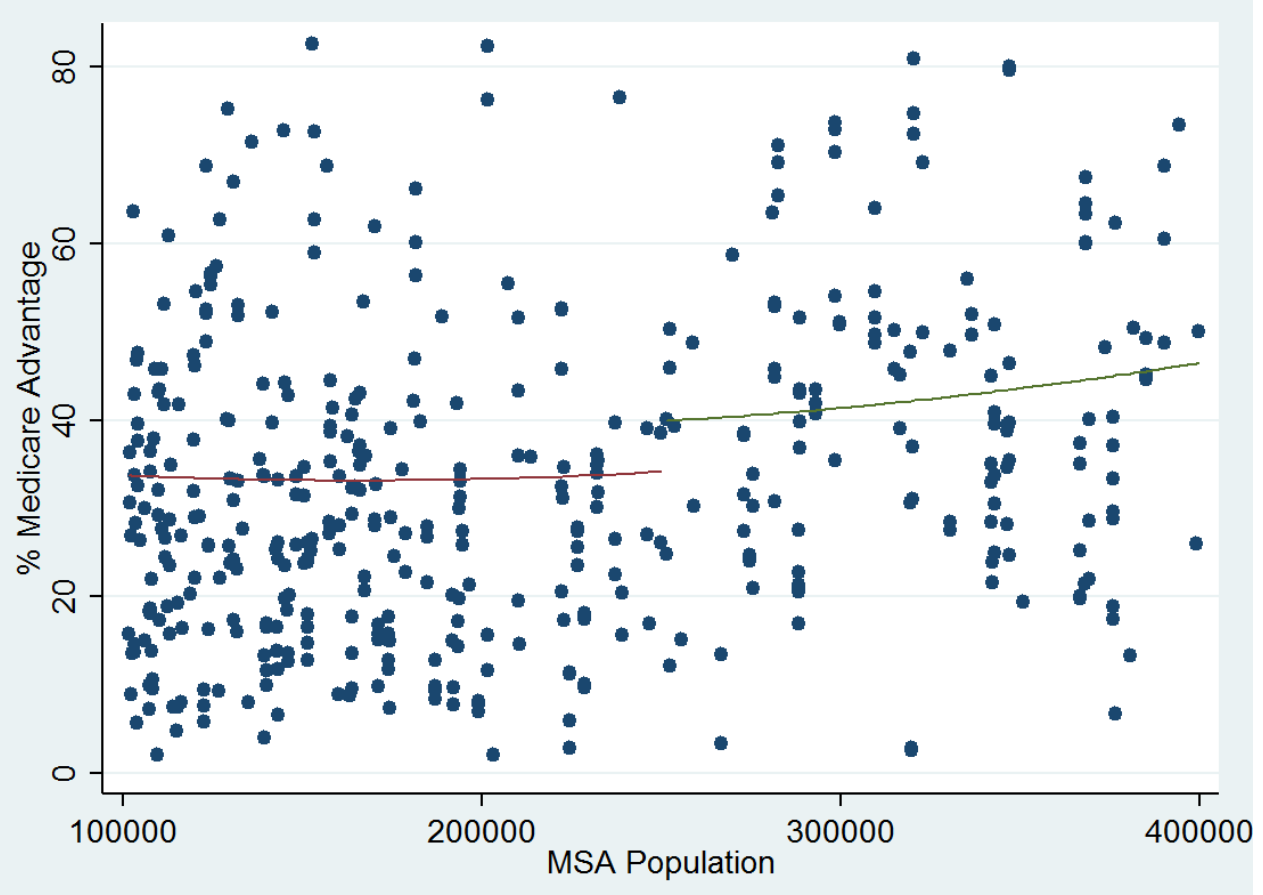

Figure 2: County-Average Opioid Prescription Rate in Medicare, By MSA Population

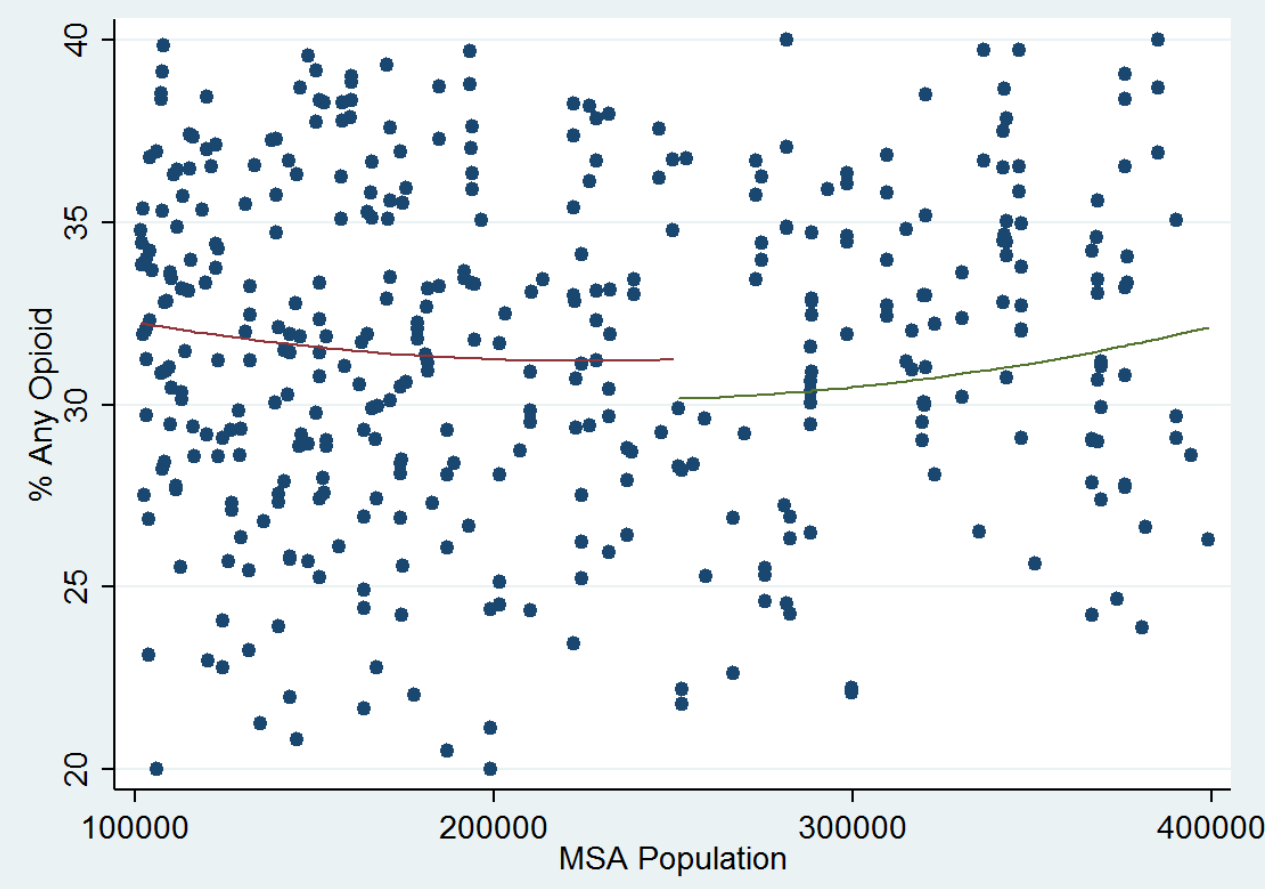




\section{Table 1a: Means of Dependent Variables}

All Beneficiaries

In MA-PD plan

Any opioid

Any opioid from high prescriber

Number of beneficiaries

Number of counties

Beneficiaries with Any Opioid

In MA-PD plan

$>7$ days opioids

Number of beneficiaries

Number of counties

\begin{tabular}{|c|c|c|c|c|c|}
\hline \multirow[b]{2}{*}{$\underline{\text { All Beneficiaries }}$} & \multirow[b]{2}{*}{$\begin{array}{l}\text { All non-rural } \\
\text { Medicare }\end{array}$} & \multicolumn{4}{|c|}{ Beneficiaries from MSAs with 100k-400k Population } \\
\hline & & All & $\begin{array}{c}\text { Below 250k } \\
\text { population }\end{array}$ & $\begin{array}{c}\text { Above } 250 \mathrm{k} \\
\text { population }\end{array}$ & $\begin{array}{l}\mathrm{p} \text {-value of } \\
\text { difference }\end{array}$ \\
\hline In MA-PD plan & 0.471 & 0.374 & 0.302 & 0.439 & $<0.001$ \\
\hline Any opioid & 0.291 & 0.313 & 0.319 & 0.308 & 0.068 \\
\hline Any opioid from high prescriber & 0.029 & 0.042 & 0.045 & 0.040 & 0.134 \\
\hline Number of beneficiaries & 2835088 & 536481 & 256436 & 280045 & \\
\hline Number of counties & 1084 & 407 & 244 & 163 & \\
\hline \multicolumn{6}{|l|}{ Beneficiaries with Any Opioid } \\
\hline In MA-PD plan & 0.452 & 0.352 & 0.282 & 0.419 & $<0.001$ \\
\hline$>7$ days opioids & 0.675 & 0.684 & 0.686 & 0.683 & 0.620 \\
\hline Number of beneficiaries & 824733 & 168099 & 81821 & 86278 & \\
\hline Number of counties & 1084 & 407 & 244 & 163 & \\
\hline \multicolumn{6}{|c|}{ Beneficiaries with Any Opioid From High Prescribers } \\
\hline In MA-PD plan & 0.456 & 0.339 & 0.269 & 0.412 & $<0.001$ \\
\hline$>7$ days opioids from high prescriber & 0.944 & 0.939 & 0.939 & 0.939 & 0.954 \\
\hline Number of beneficiaries & 82806 & 22654 & 11566 & 11088 & \\
\hline Number of counties & 1062 & 396 & 235 & 161 & \\
\hline
\end{tabular}

Beneficiaries with Any Opioid From High Prescribers

Notes: High prescriber defined as the top $1 \%$ in terms opioid prescriptions.

Sample includes beneficiaries enrolled in same plan and alive all of 2014.

p-values based on heteroscedasticity-consistent standard errors clustered by county. 
Table 1b: Means (and Standard Deviations) of Independent Variables

\begin{tabular}{|c|c|c|c|c|c|}
\hline \multirow[b]{2}{*}{ Individual beneficiary characteristics } & \multirow[b]{2}{*}{$\begin{array}{l}\text { All non-rural } \\
\text { Medicare }\end{array}$} & \multicolumn{4}{|c|}{ Beneficiaries from MSAs with $100 \mathrm{k}-400 \mathrm{k}$ Population } \\
\hline & & All & $\begin{array}{l}\text { Below 250k } \\
\text { population }\end{array}$ & $\begin{array}{c}\text { Above } 250 \mathrm{k} \\
\text { population }\end{array}$ & $\begin{array}{l}\mathrm{p} \text {-value of } \\
\text { difference }\end{array}$ \\
\hline \multirow[t]{2}{*}{ Age } & 75.883 & 75.714 & 75.746 & 75.685 & 0.425 \\
\hline & $(7.087)$ & $(6.981)$ & $(6.959)$ & $(7.002)$ & \\
\hline Female & 0.596 & 0.597 & 0.601 & 0.593 & 0.017 \\
\hline Black & 0.066 & 0.043 & 0.041 & 0.044 & 0.675 \\
\hline \multicolumn{6}{|l|}{ County characteristics } \\
\hline \multirow[t]{2}{*}{ Opioid prescriptions/person } & 0.754 & 0.957 & 0.984 & 0.933 & 0.206 \\
\hline & $(0.299)$ & $(0.342)$ & $(0.357)$ & $(0.326)$ & \\
\hline \multirow{2}{*}{ County average risk score } & 0.985 & 0.937 & 0.928 & 0.946 & 0.048 \\
\hline & $(0.084)$ & $(0.066)$ & $(0.075)$ & $(0.055)$ & \\
\hline \multirow[t]{2}{*}{ Primary care MDs/1000 people } & 0.805 & 0.747 & 0.747 & 0.747 & 0.993 \\
\hline & $(0.291)$ & $(0.318)$ & $(0.350)$ & $(0.285)$ & \\
\hline \multirow[t]{2}{*}{$\%$ in poverty } & 0.144 & 0.158 & 0.163 & 0.153 & 0.068 \\
\hline & $(0.047)$ & $(0.043)$ & $(0.044)$ & $(0.041)$ & \\
\hline \multirow[t]{2}{*}{ Median income (100000 \$) } & 0.578 & 0.494 & 0.477 & 0.510 & 0.005 \\
\hline & $(0.144)$ & $(0.085)$ & $(0.076)$ & $(0.091)$ & \\
\hline \multirow[t]{2}{*}{$\%$ disabled } & 0.099 & 0.119 & 0.122 & 0.117 & 0.250 \\
\hline & $(0.029)$ & $(0.031)$ & $(0.031)$ & $(0.031)$ & \\
\hline \multirow[t]{2}{*}{$\%$ obese } & 0.273 & 0.298 & 0.297 & 0.299 & 0.784 \\
\hline & $(0.045)$ & $(0.044)$ & $(0.044)$ & $(0.044)$ & \\
\hline \multirow[t]{2}{*}{$\%$ diabetic } & 0.010 & 0.011 & 0.010 & 0.011 & 0.783 \\
\hline & $(0.002)$ & $(0.002)$ & $(0.002)$ & $(0.002)$ & \\
\hline \multirow[t]{2}{*}{$\%$ Medicaid } & 0.222 & 0.223 & 0.228 & 0.219 & 0.304 \\
\hline & $(0.081)$ & $(0.066)$ & $(0.067)$ & $(0.065)$ & \\
\hline \multirow[t]{2}{*}{ Land area/population } & 0.335 & 0.724 & 0.933 & 0.532 & $<0.001$ \\
\hline & $(0.771)$ & $(1.238)$ & $(1.393)$ & $(1.041)$ & \\
\hline Medicaid expansion state & 0.514 & 0.369 & 0.386 & 0.353 & 0.605 \\
\hline \multicolumn{6}{|l|}{$\underline{\text { Hospital market characteristics }}$} \\
\hline Hirschman-Herfindahl Index & 0.383 & 0.526 & 0.563 & 0.491 & $<0.001$ \\
\hline Bed capacity index & 1.000 & 0.758 & 0.761 & 0.756 & 0.908 \\
\hline For-profit & 0.147 & 0.136 & 0.157 & 0.116 & 0.179 \\
\hline Non-profit & 0.762 & 0.758 & 0.718 & 0.795 & 0.041 \\
\hline Teaching & 0.370 & 0.283 & 0.241 & 0.321 & 0.034 \\
\hline System & 0.792 & 0.748 & 0.729 & 0.765 & 0.310 \\
\hline Hospital integrated w/MDs & 0.435 & 0.461 & 0.452 & 0.470 & 0.704 \\
\hline 0-100 bed hospital & 0.056 & 0.074 & 0.077 & 0.071 & 0.485 \\
\hline 301+ bed hospital & 0.562 & 0.503 & 0.446 & 0.556 & 0.002 \\
\hline Number of beneficiaries & 2835088 & 536481 & 256436 & 280045 & \\
\hline Number of counties & 1084 & 407 & 244 & 163 & \\
\hline
\end{tabular}


Table 2: Distribution of Opioid Prescriptions

Across Prescribers

\begin{tabular}{lcc} 
Prescribers $(\mathrm{N}=1126373)$ & $\begin{array}{c}\text { Number of } \\
\text { Prescriptions }\end{array}$ & $\begin{array}{c}\text { Share of } \\
\text { Prescriptions Written } \\
\text { In This Interval }\end{array}$ \\
\cline { 3 - 3 } Average & 14.759 & \\
Top 1\% cutoff & 217 & 0.269 \\
Top 2\% cutoff & 142 & 0.387 \\
Top 3\% cutoff & 108 & 0.471 \\
Top 5\% cutoff & 71 & 0.590 \\
Top 10\% cutoff & 34 & 0.754 \\
Top 25\% cutoff & 8 & 0.931 \\
Top 50\% cutoff & 1 & 0.993 \\
\hline
\end{tabular}




\section{Table 3: Effect of Urban Floor County on MA-PD Enrollment (First Stage) and Effects of MA-PD Enrollment on Opioid Use Reported in Percentage Points}

\begin{tabular}{|c|c|c|c|c|c|}
\hline \multirow{4}{*}{ In MA-PD plan } & \multirow{2}{*}{$\begin{array}{l}\text { In MA-PD } \\
\text { Plan } \\
(1)\end{array}$} & \multicolumn{2}{|c|}{ Any Opioid } & \multicolumn{2}{|c|}{$\begin{array}{c}\text { >7 Days Opioid } \\
\text { Conditional on Any } \\
\text { Opioid }\end{array}$} \\
\hline & & (2) & (3) & (4) & (5) \\
\hline & & $-2.752^{\star \star \star}$ & $-11.593^{\star \star}$ & $-1.445^{\star \star \star}$ & 0.065 \\
\hline & & $(0.184)$ & $(4.629)$ & $(0.333)$ & $(5.454)$ \\
\hline \multirow[t]{2}{*}{ Urban floor county } & $11.882^{\star \star *}$ & & & & \\
\hline & $(2.748)$ & & & & \\
\hline \multirow[t]{2}{*}{ County poverty rate } & $-0.905^{\star \star}$ & $0.513^{\star \star *}$ & $0.430^{\star \star *}$ & -0.111 & -0.102 \\
\hline & $(0.450)$ & $(0.104)$ & $(0.124)$ & $(0.098)$ & $(0.106)$ \\
\hline \multirow[t]{2}{*}{ County disability rate } & 0.343 & $0.302^{\star \star \star}$ & $0.350^{\star \star \star}$ & 0.108 & 0.098 \\
\hline & $(0.474)$ & $(0.090)$ & $(0.099)$ & $(0.115)$ & $(0.122)$ \\
\hline \multirow[t]{2}{*}{ County obesity rate } & $0.647^{\star *}$ & $0.175^{\star \star \star}$ & $0.227^{\star \star \star}$ & $0.217^{\star \star \star}$ & $0.208^{\star \star \star}$ \\
\hline & $(0.288)$ & $(0.065)$ & $(0.075)$ & $(0.065)$ & $(0.067)$ \\
\hline \multirow[t]{2}{*}{ County average risk score } & $0.546^{\star \star \star}$ & -0.017 & 0.034 & $0.146^{\star \star \star}$ & $0.138^{\star \star \star}$ \\
\hline & $(0.193)$ & $(0.033)$ & $(0.042)$ & $(0.036)$ & $(0.050)$ \\
\hline Estimator & OLS & OLS & IV & OLS & IV \\
\hline Mean of dependent variable & 37.388 & 31.334 & 31.334 & 68.435 & 68.435 \\
\hline Number of observations & 536481 & 536481 & 536481 & 168099 & 168099 \\
\hline Number of counties & 407 & 407 & 407 & 407 & 407 \\
\hline
\end{tabular}

Notes: Heteroscedasticity-consistent standard errors clustered by county. 
Table 4: Effect of Urban Floor County on MA-PD Enrollment (First Stage) and Effects of MA-PD Enrollment on Opioid Use, Ordered By Top 1\% of Prescribers Reported in Percentage Points

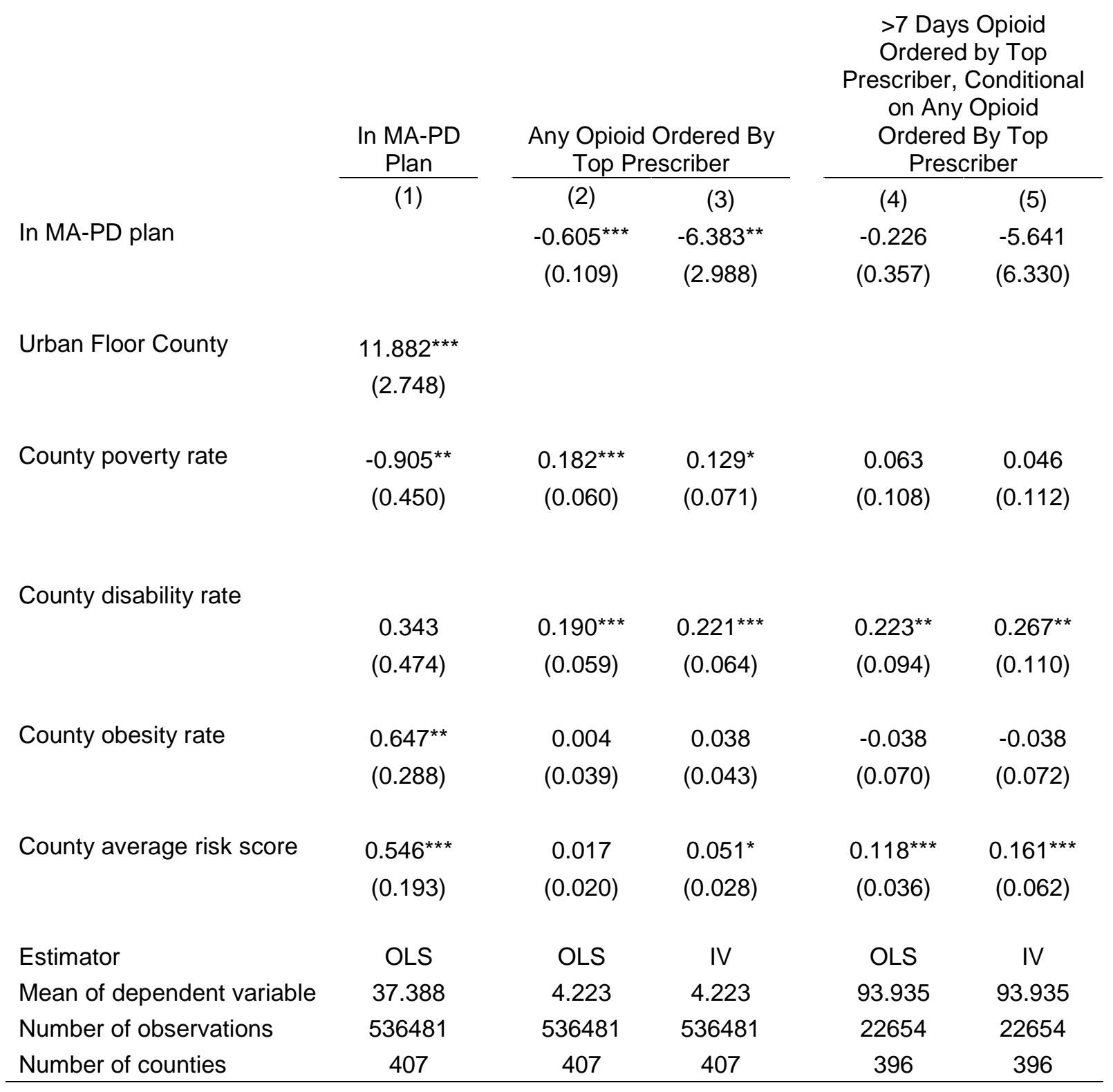

Notes: Heteroscedasticity-consistent standard errors clustered by county. 
Table 5: Effect of Urban Floor County on MA-PD Enrollment (First Stage) and IV Effects of MA-PD Enrollment on Any Opioid Prescription, Alternative Models Reported in Percentage Points

\begin{tabular}{|c|c|c|c|c|c|c|c|c|}
\hline & $\begin{array}{l}\text { In MA-PD } \\
\text { Plan }\end{array}$ & $\begin{array}{c}\text { Any opioid } \\
\text { rx }\end{array}$ & $\begin{array}{l}\text { In MA-PD } \\
\text { Plan }\end{array}$ & $\begin{array}{c}\text { Any opioid } \\
\text { rX }\end{array}$ & $\begin{array}{l}\text { In MA-PD } \\
\text { Plan }\end{array}$ & $\begin{array}{c}\text { Any opioid } \\
\text { rX }\end{array}$ & $\begin{array}{l}\text { In MA-PD } \\
\text { Plan }\end{array}$ & $\begin{array}{c}\text { Any opioid } \\
\text { rx }\end{array}$ \\
\hline & (1) & (2) & (3) & (4) & (5) & (6) & (7) & (8) \\
\hline \multirow[t]{2}{*}{ In MA-PD plan } & & $-12.960^{\star *}$ & & $-10.403^{\star \star}$ & & $-23.693^{\star \star \star}$ & & $-6.692^{\star \star}$ \\
\hline & & $(5.177)$ & & $(4.412)$ & & $(7.224)$ & & $(2.885)$ \\
\hline \multirow[t]{2}{*}{ Urban Floor County } & $11.425^{\star \star \star}$ & & $11.477^{\star \star \star}$ & & $13.900^{\star \star \star}$ & & $11.725^{\star \star \star}$ & \\
\hline & $(2.729)$ & & (2.643) & & (3.835) & & $(2.840)$ & \\
\hline \multirow[t]{2}{*}{ MSA population $\left(10^{\wedge}-6\right)$} & 0.032 & 0.025 & $-1.418^{\star}$ & $-0.319 \star \star$ & $-39.648^{\star \star \star}$ & $-7.623^{\star \star}$ & -1.112 & -0.093 \\
\hline & $(0.159)$ & $(0.036)$ & $(0.733)$ & $(0.144)$ & $(11.832)$ & (3.874) & $(0.779)$ & $(0.090)$ \\
\hline \multirow{2}{*}{ MSA population^2 $\left(10^{\wedge}-12\right)$} & & & $2.880^{*}$ & $0.688^{\star \star}$ & $75.706^{\star \star \star}$ & $14.311^{*}$ & 2.277 & 0.202 \\
\hline & & & $(1.499)$ & $(0.308)$ & $(23.488)$ & $(7.731)$ & $(1.591)$ & $(0.186)$ \\
\hline County average & & & $-1.178^{\star \star \star}$ & $0.411^{\star \star *}$ & & & & \\
\hline opioid prescription rate & & & $(0.338)$ & $(0.099)$ & & & & \\
\hline $\begin{array}{l}\text { Estimator } \\
\text { Sample }\end{array}$ & \multicolumn{2}{|c|}{ Full sample } & \multicolumn{2}{|c|}{ Full sample } & \multicolumn{2}{|c|}{$\begin{array}{l}\text { MSAs with population } \\
\text { between 200-300k }\end{array}$} & \multicolumn{2}{|c|}{$\begin{array}{l}\text { Opioid-naive Enrollees } \\
\text { Only }\end{array}$} \\
\hline Number of observations & 536481 & 536481 & 536481 & 536481 & 139184 & 139184 & 370529 & 370529 \\
\hline Number of counties & 407 & 407 & 407 & 407 & 97 & 97 & 407 & 407 \\
\hline
\end{tabular}




\section{$\underline{\text { References }}$}

Afendulis CC, Chernew ME, Kessler DP. The effect of Medicare Advantage on hospital admissions and mortality. Am J Health Econ 2017;3(2):254-79.

Baker, LC. HMOs and fee for service health care expenditures: evidence from Medicare. Journal of Health Economics 1997;16(4): 453-81.

Bao Y, Wen K, Johnson P, Jen PJ, Meisel ZF, et al. Assessing the Impact of State Policies For Prescription Drug Monitoring Programs on High-Risk Opioid Prescriptions. Health Aff. 2018;37(10):1596-1604.

Barnett ML, Olenski AR, Thygeson NM, Ishisaka D, Wong S, Jena AB, et al. A health plan's formulary led to reduced use of extended-release opioids but did not lower overall opioid use. Health Aff. 2018;37(9):1509-16.

Buchmueller TC, Carey C. The effect of prescription drug monitoring programs on opioid utilization in medicare. 2017 NBER Working Paper 23148, available at http://www.nber.org/papers/w23148, accessed September 11, 2018.

Cabral M, Geruso M, Mahoney N. Do Larger Health Insurance Subsidies Benefit Patients or Producers? Evidence from Medicare Advantage. American Econ Review 2018;108(8):2048-87.

Chen JH, Humphreys K, Shah NH, Lembke A. Distribution of opioids by different types of Medicare prescribers. JAMA Int Med. 2016;176(2):259-61.

Chernew M, DeCicca P, Town R. Managed Care and Medical Expenditures of Medicare Beneficiaries. Journal of Health Economics 2008;27(6):1451-61.

Dasgupta N, Beletsky L, Ciccarone D. Opioid crisis: no easy fix to its social and economic determinants. AJPH. 2018;108(2):182-6.

Dowell D, Zhang K, Noonan RK, Hockenberry JM. Mandatory provider review and pain clinic laws reduce the amounts of opioids prescribed and overdose death rates. Health Aff. 2016;35(10):1876-83.

Duggan M, Starc A, Vabson B. Who Benefits When the Government Pays More? Pass-through in the Medicare Advantage Program. J Pub Econ 2016;141(1):50-67.

Garcia MC, Dodek AB, Kowalski T, Fallon J, Lee SH, Iademarco MF, et al. Declines in opioid prescribing after a private insurer policy change - Massachusetts 2011-2015, MMWR Morb Mortal Wkly Rep. 2016. 65(41):1125-31.

Guy GP, Zhang K, Bohm MK, Losby J, Lewis B, Young R, et al. Vital signs: changes in opioid prescribing in the United States, 2006-2015. MMWR Morb Mortal Wkly Rep. 2017;66(26):697704. 
HHS OIG. Opioids In Medicare Part D. OEI-02-17-00250, data brief 2017. Available at https://oig.hhs.gov/oei/reports/oei-02-17-00250.pdf, accessed September 11, 2018.

Jena AB, Goldman D, Weaver L, Karaca-Mandic P. Opioid prescribing by multiple providers in Medicare: retrospective observational study of insurance claims. BMJ. 2014;348:1393-1404.

Kaiser Family Foundation. Fact sheet: The Medicare Part D prescription drug benefit. 2017. Available at https://www.kff.org/medicare/fact-sheet/the-medicare-prescription-drug-benefit-factsheet/, accessed September 10, 2018.

Laverdier D, Pereyda M, Silva J. Changing course: The role of health plans in curbing the opioid epidemic. California Health Care Foundation 2016. Available at https://www.chcf.org/publication/changing-course-the-role-of-health-plans-in-curbing-the-opioidepidemic/, accessed September 10, 2018.

Liu Y, Logan JE, Paulozzi LJ, Zhang K, Jones CM. Potential misuse and inappropriate prescription practices involving opioid analgesics. Am J Man Care. 2013;19(8):648-58.

Paulozzi LJ, Jones CM, Mak KA, Rudd RA. Vital signs: overdoses of prescription opioid pain relievers - United States, 1999-2008. MMWR Morb Mortal Wkly Rep. 2011;60(43):1487-92.

Powell D, Pacula RL, Taylor E. How increasing medical access to opioids contributes to the opioid epidemic: evidence from Medicare Part D. 2015 NBER working paper 21072. Available at http://www.nber.org/papers/w21072, accessed September 11, 2018.

Sacco LN, Duff JH, Sarata AK. Prescription drug monitoring programs. Congressional Research Service 2018 R42593.

Schell M, Currie J. Addressing the Opioid Epidemic: Is There a Role for Physician Education? 2017 NBER Working Paper 23645. Available at htttp://www.nber.org/papers/23645, accessed September 11, 2018.

Starc A, Town RJ. Externalities and benefit design in health insurance. 2018 NBER working paper 21783. Available at http://www.nber.org/papers/21783, accessed September 11, 2018.

UnitedHealth Group, Long-term use of opioid prescriptions and prospects for innovation in prevention, treatment, and pain management. Enterprise Research and Development Clinical Report. 2017. Available at https://www.unitedhealthgroup.com/content/dam/UHG/PDF/2017/UNH-Clinical-InnovationReport-Opioids.pdf?la=en, accessed September 11, 2018.

Wen H, Schackman BR, Aden B, Bao Y. States with prescription drug monitoring mandates saw a reduction in opioids prescribed to Medicaid enrollees. Health Aff. 2017;36(4):733-41. 
Zhou C, Florence CS, Dowell D. Payments for opioids shifted substantially to public and private insurers while consumer spending declined, 1999-2012. Health Aff. 2016;35(5);824-31. 